\title{
Histological Characteristics of Ligaments between Middle Ear and Temporomandibular Joint
}

\author{
Metin Sencimen ${ }^{a}$ \\ Altan Varol ${ }^{b}$ \\ Baris Baykalc \\ Hasan Ayberk Altug ${ }^{d}$ \\ Necdet Dogan ${ }^{a}$ \\ Sermet Sahine \\ Kemal Murat Okcu \\ Bulent Yalcin ${ }^{f}$
}

\section{ABSTRACT}

Objectives: To examine histological aspects of the ligaments between the middle ear and temporomandibular joint and suppose a theoretical role of their structural characteristics on mobility of mallear ossicle.

Methods: The ligaments were obtained by microdissection of middle cranial fossa on both sites of 15 cadavers fixed in formalin solution and were sectioned longitudinally (7-10 $\mu \mathrm{m}$ thickness). The sections were stained with Verhoff's Van Gieson's stain (VVG) for demonstration of elastic fibers and visualized at X2.5 and X10 magnifications under light microscopy.

Results: Anterior mallear ligament (AML) and sphenomandibular ligaments (SML) were consisted of collagen fibres in analyzed specimens. The discomallear ligament (DML) was constituted of rich collagenous fibres. One specimen of DML harvested between petrotympanic fissure and retrodiscal-capsular intersection site contained elastic fibers dispersed in cotton-bowl appearance between collagen fibers. In the light of functional tests performed in previous studies, it could be extrapolated that presence of elastic fibers in the DML may prevent excessive forces conducted to mallear head by elongation of elastic fibers.

Conclusions: Collagenous fibres have no ability to stretch along their axis which may lack compensatory mechanism to prevent mallear head mobility. (Eur J Dent 2009;3:280-284)

Key words: Anterior mallear ligament; Discomallear ligament; Sphenomandibular ligament; Collagen fibres; Elastic fibres; Malleus.

a Department of Oral and Maxillofacial Surgery, Gulhane Military Medical Academy, Ankara, Turkey.

b Department of Oral and Maxillofacial Surgery, Faculty of Dentistry, Marmara University, Istanbul, Turkey.

Department of Histology, Gulhane Military Medical Academy, Ankara, Turkey.

d Etimesgut Military Hospital Dental Service, Ankara, Turkey.

e Department of Periodontology, Gulhane Military Medical Academy, Ankara, Turkey. $f$ Department of Anatomy, Gulhane Military Medical Academy, Ankara, Turkey.

- Corresponding author: Metin Sencimen

Assistant Professor

Gulhane Military Medical Academy

Department of Oral and Maxillofacial Surgery

Etlik, 06018, Ankara, Turkey

Phone:+90 3123046069

Fax:+90 3123046020

E-mail: metinsencimendayahoo.com 


\section{INTRODUCTION}

A close relationship between TMJ and structures of the middle ear ${ }^{1-10}$ has been explained by the presence of the anterior mallear ligament (AML), the sphenomandibular ligament (SML) and the discomallear ligament (DML).,2,8,11-13 In the past, AML was accepted as an initial ligament lying between the middle ear and articular disc (AD) of TMJ. ${ }^{13}$

However, further investigations discovered that two distinct ligaments form the AML. ${ }^{12}$ The anatomic relations and functional properties of $D M L, A M L$, and SML are described comprehensively in well-documented studies., ${ }^{5,8,12,14}$ On the other hand, different opinions exist about histological characteristics of these ligaments. ${ }^{6,8,9,12,14-17}$ Various investigators have recognized $A M L$ to be consisted of muscular fibers, fibrotic tissue bands, fibro-elastic bands and lastly collagenous fibers since the last century. $3,6,14,16,17$

The DML is a free ligament, lying between the malleus and the TMJ, 5,8,12,18 which was shown to have a total structural difference from the AML. ${ }^{19}$ These ligaments were exposed to various traction and stretching tests in the cadaveric studies to discover whether they were responsible for mallear mobility by experimental simulation of discal or condylar translation. ${ }^{6,9,17-19}$ A number of researches supposed that these ligaments were comprised of collagenous fibres ${ }^{9,12}$ whereas the others supported that only fibro-elastic fibres could transmit traction forces of TMJ and cause mobility of the mallear ossicle. ${ }^{6,8}$ For that reason, we conducted a histological study on the ligaments between the $A D$ and the malleus to clarify the weight of histological properties on mobility of the mallear ossicle in the middle ear.

\section{MATERIALS AND METHODS}

15 adult skulls, fixed in a formalin solution, with undamaged TMJs were used in the presented study. The cadavers were obtained from Gulhane Military Medical Academy, Department of Anatomy, Ankara, Turkey. All micro dissections were carried under a dissection microscope. Dissection was initiated by removing dura mater and periosteum of middle cranial fossa. Then malleus and incus were explored by entering middle ear cavity through the arcuate eminence. With protection of malleus and incus, petrous part of the temporal bone was removed and the mandibular fossa was exposed. The components of middle ear, the ligaments lying anterior to malleus, the $A D$, and the capsule were explored.

Anterior surface of the petrous part was removed subsequently to follow posteromedial section of TMJ. Little forceps were used to collect bone remnants. By this way, posteromedial and retrodiscal tissues of TMJ were completely exposed. AML and DML were excised and the intact ones were processed for histologic examination to evaluate their histologic structure and relations with surrounding tissues.

The ligaments, which were already fixed in 10\% buffered formal-saline solution were sectioned longitudinally (7-10 $\mu \mathrm{m}$ thickness) for examination under light microscopy. The sections were stained with Verhoff's Van Gieson's stain (VVG) (for elastic fibres). The sections were visualised at X2.5 and X10 magnifications under a Leica DMI 6000 microscope (Leica, Germany) using the software Leica Application Suite (Leica, Germany).

\section{RESULTS}

By VVG stain, the elastic fibres are observed in blue colour and the collagen fibres in red colour. Histologically, the SML and the AML were composed of collagen bundles and fibrocytes between them. The DML was composed of collagen, elastic fibres, and fibrocytes. The elastic and collagen fibres were arranged in an alternating interwoven manner. The fibrocytes were seen running in the direction of the connective tissue fibres.

\section{AML and SML}

The AML was consisted of collagenous structure (Figure 1). The collagenous fibres were running as filaments in some part of the stained specimens, or they were dispersed in denser fashion as thick bands (Figure 1). However, no evidence of elastic fibres was found in none of the examined sections. Nuclei of fibrocytes and collagenous filaments straddling perpendicularly were observed clearly in the thicker collagenous bands. In addition, lumens of capillary vessels were observed particularly between collagenous bands (Figure 1).

SML consisted totally of collagen bundles (Figure 2). The collagenous bundles were running in parallel fashion. Cluster of adipose cells were ob- 
served adjacent to collagenous filaments. Lumen of capillaries was detected dispersed amid collagen fibrils (Figure 2).

\section{DML}

The DML was constituted of rich collagenous fibres in analysed sections (Figures 3 and 4). Nuclei of fibrocytes were observed clearly within the collagen bundles. Interestingly, one specimen, that was harvested between petrotympanic fissures and at the insertion sites of DML to articular disc-capsular ligament unit, contained elastic fibres dispersed as cotton-bowls amid the collagenous filaments (Figures 3 and 4). However, no
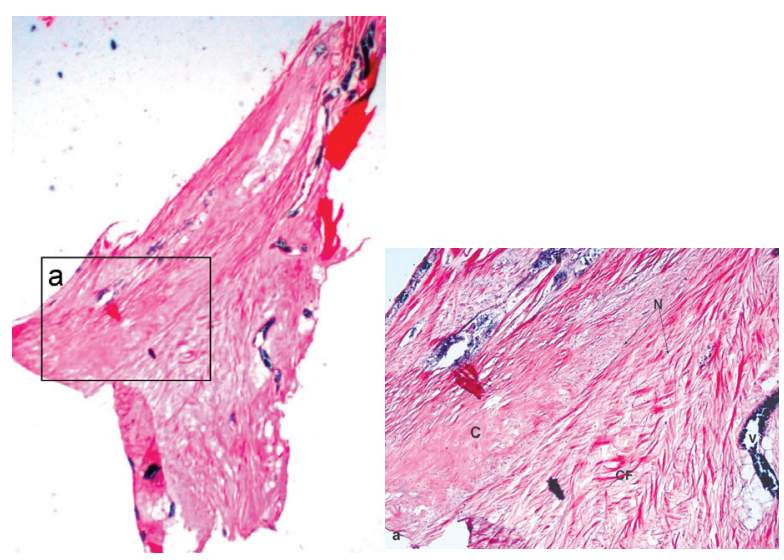

Figure 1. Micrograph of an AML specimen (x2.5). Presence of excessive collagen fibrils is evident throughout the specimen. $\mathrm{N}$-Nuclei of fibrocytes in the AML, V-lumen of a capillary vessel, C-Collagen bundles.

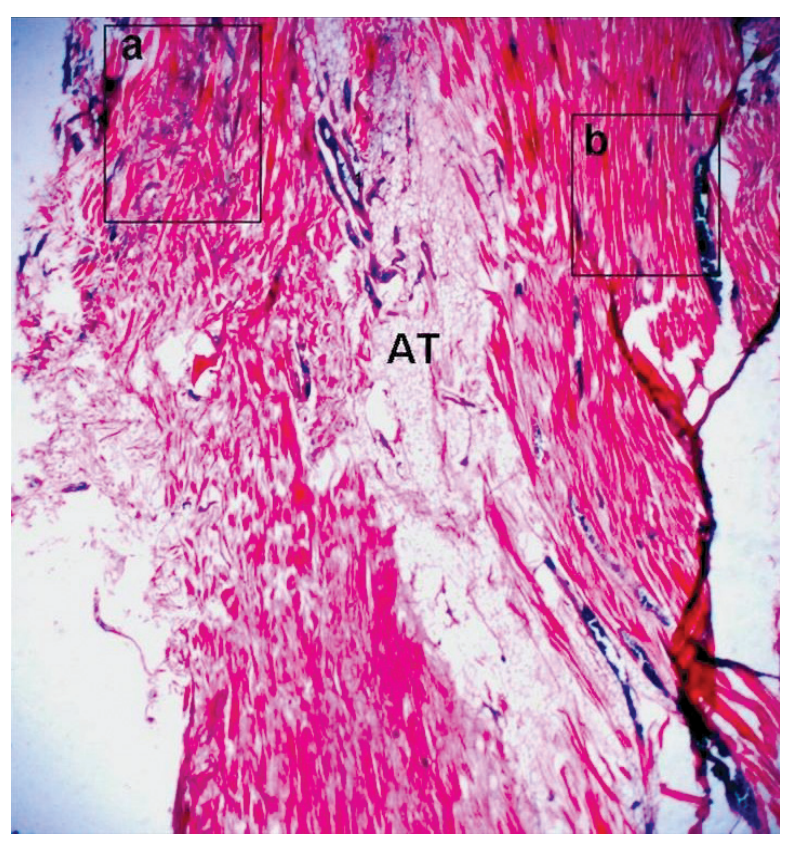

Figure 3. Microphotograph of a specimen containing a unit of SML-DML. a. The DML is running at the left section. Elastic fibers are supernumerary in the "a" square b. The SML consisted of collagen fibers is indicated by the "b" square. Two ligaments are separated with an areolar adipose tissue (AT) (X2.5). evidence of elastic structure was found in the part of the DML spanning between the malleus and petrotympanic fissure.

\section{DISCUSSION}

Mammalian Meckel's cartilage, which is derived from the first brachial arch, consists of calcified and uncalcified segments. ${ }^{20}$ It is well known that the anterior portion that is anterior to the mental foramen and the auricular portion of Meckel's cartilage contribute to bone formation of the mandible, the malleus and incus by endochondral ossification. ${ }^{20}$ By contrast, the midportion of Meckel's cartilage, in the soft tissue, eventually forms the SML. ${ }^{21} \mathrm{AML}$ and $\mathrm{DML}$ were demonstrated, in many studies, lying from malleus to petrotympanic fissure. $8,12,14$ Such a relationship of the ligaments with adjacent anatomic structures set a hypothesis about possible damage to the middle

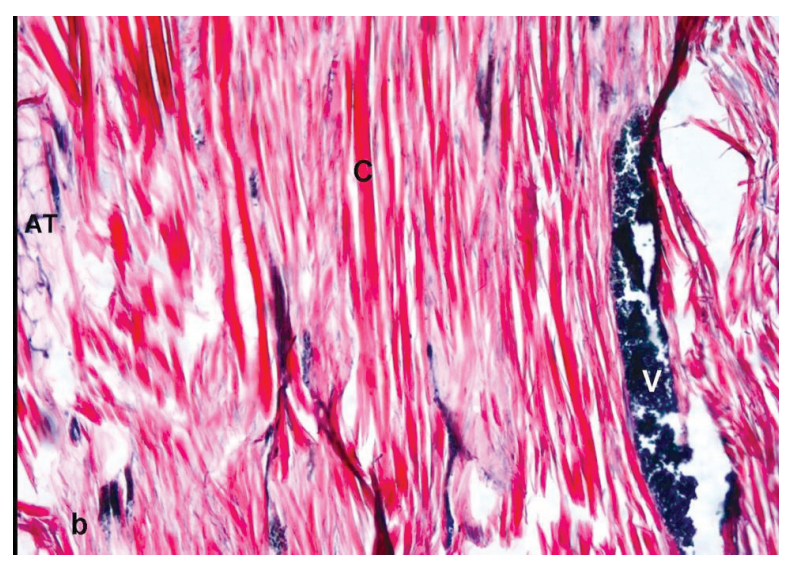

Figure 2. Microphotograph of a SML specimen. Collagen bundles are oriented in perpendicular running fashion that is parallel to the longitudinal section of the ligament. C-Collagen bundles: V-Lumen of a capillary vein, AT-Adipose tissue (x10).

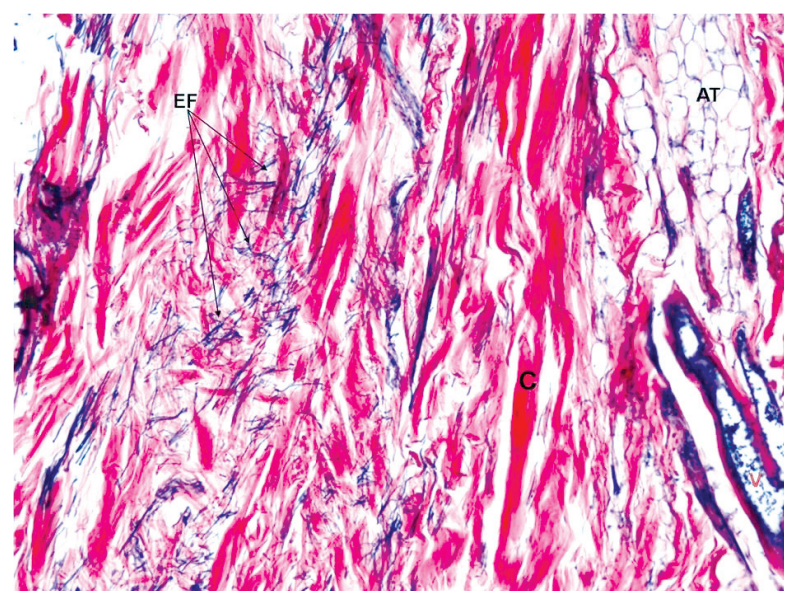

Figure 4. Microphotograph of DML magnified from the "a" rectangle in Fig 3. C: Collagen bundles, EF: Elastic fibers in the DML at an interwowen manner, AT: Adipose tissue, V: Vasculature $(x 10)$. 
ear ossicles and the tympanic membrane. ${ }^{12,19}$ That hypothesis was based on the fact that mallear movement would be responsible for such a dilemma that might be caused by invasive TMJ surgery or Anterior displacement of the AD. ${ }^{19,22}$ Another hypothesis for this phenomenon was role of extreme distraction of mandibular ramus that incorporated in stretching of AML by intense traction of SML. ${ }^{19}$

The previous studies mentioned that application of strain forces on DML caused mobility of mallear ossicle. 6,9,23 Mallear movement by SML stretching was observed in specimens among 50 cadavers. ${ }^{12}$ Kim stretched DML and found no movement; in contrary, noteworthy mobility of the malleus was obtained by AML stretching. ${ }^{17}$ The same findings were proved in our studies in which we detected movement in one third of 15 cadavers. ${ }^{19}$ In the light of these studies, histologic properties of these ligaments were thought to have a possible role on the mallear movement. At the same time, we observed that this issue is studied only be means of ligament stretching. The stretching tests are partially doubtful, since the adherences or the bony impingements in the petrotympanic fissure are removed during cadaveric dissections to free these ligaments.

Therefore, the reported studies may be suspicious to some extent since mallear movement would not have occurred unless full unearthing or bony dissection for these ligaments was accomplished in the middle cranial fossa. That important fact made us to investigate the ligaments histologically to establish a theory for explaining mallear movement by grounds of the previous stretching tests and histological properties of the filaments.

The most recent view about histologic properties of AML and DML was that they consisted of collagenous filaments. ${ }^{15}$ In our study, we found exactly the same findings. The AML did not contain any elastic fibres. Elastic fibres were observed in the DML sections. The elastic fibres were dispersed throughout the stroma of ligament as cottonbowl appearance. The ligaments of any filament composition connected to the malleus can initiate mallear mobility without taking into account the adherences in the petrotympanic fissure.

However, the abundant elastic fibres in the DML may be responsible for compensation of strain forces on this ligament and may reflect minor forces to the mallear head. The collagenous ligaments are lacking such a compensatory mechanism and may reproduce major movement of malleus by direct transformation of strain forces. This hypothesis could be accepted when histological characteristics of the ligaments are judged. Accordingly, the same mechanism was observed in the first part of this study that covered anatomic and functional aspects of these ligaments.

\section{CONCLUSIONS}

The AML forms "pulling" effect on the structures which it is inserting by initiation and termination of a traction force. The DML differs in its structural unity by owing additional elastic filaments. Theoretically, this special configuration is not expected to form the same strain forces as the AML does which means that the DML has a less disimpaction effect on the malleus.

\section{REFERENCES}

1. Baume LJ, Holz J. Ontogenesis of the human temporomandibular joint. 2. Development of the temporal components. J Dent Res 1970;49:864-875.

2. Burch JG. The cranial attachment sphenomandibular (tympanomandibular) ligament. Anat Rec 1966;156:433-438.

3. Coleman RD. Temporomandibular joint: relation of the retrodiscal zone to Meckel's cartilage and lateral pterygoid muscle. J Dent Res 1970;49:626-630.

4. Furstman L. The early development of the human temporomandibular joint. Am J Orthod 1963;49:672-682.

5. Komori E, Sugisaki M, Tanabe H, Katoh S. Discomallear ligament in the adult human. $J$ Craniomandib Pract 1986;4:300-305.

6. Pinto OF. A new structure related to the temporomandibular joint and middle ear. J Prosthet Dent 1962;12:95-103.

7. Rees LA. The structure and function of the mandibular joint. Br Dent J 1954;96:125-133.

8. Rodriquez Vazquez JF, Merida Velasco JR, Merida Velasco JA, Jimenez Collado J. Anatomical consideration on the discomallear ligament. J Anat 1998;192:617-621.

9. Toledo Filho JL, Zorzetto NL, Caldas Navarro JA. Structures and relationships of the anterior malleus ligament. Anat Anz Jena 1985;158:13-22.

10. Youdellis RA. The morphogenesis of the human temporomandibular joint and its associated structures. $J$ Dent Res 1966;45:182-191.

11. Loughner BA, Gremillion HA, Mahan PE, Watson RE. The medial capsule of the human temporomandibular joint. $J$ Oral Maxillofac Surg 1997;55:363-369. 
12. Loughner BA, Larkin LH, Mahan PE. Discomallear and anterior mallear ligaments: possible causes of middle ear damage during temporomandibular joint surgery. Oral Surg Oral Med Oral Pathol 1989;68:14-22.

13. Toledo Filho JL, Luiz Zorzetto N, Caldas Navarro JA. Structures and relationships of the temporomandibular joint. $J$ Oral Maxillofac Surg 1985;43:565-569.

14. Dai C, Cheng T, Wood MW, Gan RZ. Fixation and detachment of superior and anterior malleolar ligaments in human middle ear: Experimental and modeling. Hearing Res 2007;230:24-33.

15. Cunningham DJ. Cunningham's textbook of anatomy. Oxford University Press, London 1964

16. Cheynet F, Gyot L, Richard O, Layoun W, Gola R. Discomallear and malleomandibular ligaments: anatomical study and clinical applications. Surg Radiol Anat 2003;25:152-157.

17. Kim HJ, Jung HS, Kwak HH, Shim KS, Hu KS, Park HD, Park HW, Chung IH. The discomallear ligament and the anterior ligament of malleus: An anatomic study in human adults and fetuses. Surg Radiol Anat 2004;26:39-45.

18. Abe S, Ouch Y, Ide Y, Yonezu H. Perspectives on the role of the lateral pterygoid muscle and the sphenomandibular ligament in temporomandibular joint function. $J$ Craniomand Pract 1997;15:203-207.

19. Sencimen M, Yalçin B, Doḡan N, Varol A, Okçu KM, Ozan $\mathrm{H}$, Aydintuḡ YS. Anatomical and functional aspects of ligaments between the malleus and the temporomandibular joint. Int J Oral Maxillofac Surg 2008;23:919-925.

20. Bhaskar S, Weinmann J, Schour I. Role of meckel's cartilage in the development and growth of the rat mandible. $J$ Dent Res 1953;32:398-410.

21. Weinberg S, Cousens G. Meniscocondylar placation: A modified operation for surgical repositioning of the ectopic temporomandibular joint meniscus. Oral Surg Oral Med Oral Pathol 1987;63:393-402.

22. Dolwick MF, Sanders B, eds. TMJ internal derangement and arthrosis: surgical atlas. St. Louis: The CV Mosby Co, 1985:150.

23. Ioannides CA, Hoogland GA. The disco-mallear ligament: a possible cause of subjective hearing loss in patients with temporomandibular joint dysfunction. J Maxillofac Surg $1983 ; 11: 227-231$. 